\title{
Description of Evandromyia grimaldii sp. nov. (Diptera: Psychodidae), a new phlebotomine species from the state of Espírito Santo, Southeast Brazil
}

\author{
José Dilermando Andrade Filho ${ }^{1 /+}$, Israel de Souza Pinto ${ }^{2}$, Claudiney Biral dos Santos ${ }^{2}$, \\ Gustavo Mayr de Lima Carvalho'
}

'Laboratório de Leishmanioses, Instituto de Pesquisas René Rachou-Fiocruz, Av. Augusto de Lima 1715, 30190-002 Belo Horizonte, MG, Brasil ${ }^{2}$ Unidade de Medicina Tropical, Universidade Federal do Espírito Santo, Vitória, ES, Brasil

Phlebotomine sand flies present great species diversity, especially in Brazil, where there are about 300 known species. This work describes a new species of sand fly found in the Brazilian state of Espirito Santo, in the Reserva Biológica de Duas Bocas, municipality of Cariacica. Spermathecae with superficial striations and the common duct longer than the genital fork permit the inclusion of the new species in the subgenus Evandromyia s. str., series rupicola. The new species resemble Ev. rupicola from which it may be distinguished by the aspects of the spermatheca and the length of the genital filament of the male, longer in the new species.

Key words: Evandromyia grimaldii sp. nov. - sand fly - Espírito Santo - Phlebotominae -taxonomy

The Brazilian territory presents a great diversity of biomes, such as equatorial rainforest, cerrado and Atlantic Forest. As a reflection of this, there exists a great biodiversity of plants and animals, several species or groups of species being endemic, and in some particular circumstances, vectors of agents to man and other mammals, as in the case of the phlebotomine sand flies. However, with so many environmental modifications of an anthropic nature these environments have become less stable, leading to an expansion of the customary biomes of various diseases, generating diverse public health problems, such as the invasion of urban centers by leishmaniases.

This study describes a new species of sand fly found in the Brazilian state of Espírito Santo (ES), in the Reserva Biológica de Duas Bocas $\left(20^{\circ} 18^{\prime} 05^{\prime}\right.$ 'S and $\left.40^{\circ} 28^{\prime} 06^{\prime \prime} \mathrm{W}\right)$, municipality of Cariacica. The area is cover by Atlantic Forest, with an altitude of between 450-850 $\mathrm{m}$ above sea level.

\section{MATERIALS AND METHODS}

Sandflies were mounted in Berlese liquid and measured with a binocular Olympus $\mathrm{CH}-2$ microscope with the aid of a micrometer objective and the drawings were made with the help of a camera lucida. The measurements are given in micrometers. The nomenclature and classification is that proposed by Galati (2003) and the abbreviation of the names for phlebotomine genera that proposed by Marcondes (2007).

Financial support: Fapemig, Capes

+ Corresponding author: jandrade@cpqrr.fiocruz.br

Received 27 November 2008

Accepted 3 March 2009

\section{Evandromyia grimaldii sp. nov. (Figs. 1-9)}

Male (holotype) - Sand fly of medium size, measurement ca. 3,038 $(2,428 \pm 75.7 ; \mathrm{n}=2)$ in length, general color light brown. Head (Fig. 1) 353 (349 $\pm 2.1 ; n=2)$ long and $297(301 ; n=1)$ wide. Head length/head width ratio 1.19: $1(1.16 ; \mathrm{n}=1)$. Clypeus $105(111 \pm 2.1 ; \mathrm{n}=2)$ long; clypeus length/head length ratio 0.30: 1 (0.32: 1 $\pm 0.01 ; \mathrm{n}=2)$. Eye $165(148 \pm 9.2 ; \mathrm{n}=2)$ long and 105 $(109 \pm 5.7 ; \mathrm{n}=2)$ wide; eye length/head length $0.47: 1$ (0.43: $1 \pm 0.02 ; \mathrm{n}=2)$. Interocular distance $88(105 ; \mathrm{n}=$ 1). Labrum-epipharynx (LE) $203(184 \pm 7.1 ; n=2)$. LE/ head length 0.58: $1(0.53 \pm 0.01 ; n=2)$. Antenna with simple, long ascoid, reaching the apex of the segment. Antennomere lengths: AIII 322 (286 $\pm 21.9 ; \mathrm{n}=2)$; AIV 147 (137 $\pm 14.8 ; n=2) ;$ AV $154(144 \pm 9.9 ; n=2) ; A X V>$ AXVI (AXV > AXVI; $n=2)$. AIII, AIV, AV and AXIII with papilla; ratios: AIII/head length 0.91: 1 (0.82: $1 \pm$ 0.06; $\mathrm{n}=2)$; AIII/LE 1.59: 1 (1.55: $1 \pm 0.06 ; \mathrm{n}=2)$. Palpal formula 1.4.2.3.5 (1.4.2.3.5; $\mathrm{n}=2)$. Palpomere lengths: P1 39 (34 $\pm 2.1 ; \mathrm{n}=2)$; P2 137 (139 $\pm 2.1 ; \mathrm{n}=2)$; P3 154 $(160 \pm 2.1 ; \mathrm{n}=2) ; \mathrm{P} 4107(114 \pm 2.8 ; \mathrm{n}=2) ;$ P5 $378(337$ $\pm 4.9 ; \mathrm{n}=2)$. The Newstead spines are implanted in the median region of the third palpomere. Ventrocervical sensillae present. Thorax: presence of two $(1-2 ; n=2)$ proepimeral setae and anepisternal superior setae 9-11 $(10-12 ; n=2)$ in number; setae on the anterior region of the katepisternum present. Wing (Fig. 3) measurement $2,953(2,077 ; \mathrm{n}=1)$ long and $593(558 \pm 30.0 ; \mathrm{n}=2)$ at maximum width. Length/width ratio 4.97: 1 (3.73: $1 \pm$ $0.20 ; \mathrm{n}=2)$. Length of the vein sections: $\mathrm{R}_{5} 1,272(1,230$ $\pm 39.6 ; \mathrm{n}=2)$; alpha $523(509 \pm 0.0 ; \mathrm{n}=2)$; beta $212(200$ $\pm 2.8 ; \mathrm{n}=2)$; gamma $240(226 \pm 19.8 ; \mathrm{n}=2)$; delta 170 $(134 \pm 29.7 ; n=2)$. Legs: anterior, median and posterior, respectively: femur 805 (707; $\mathrm{n}=1), 777$ (742 $\pm 70.0 ; \mathrm{n}$ $=2)$ and $848(806 \pm 60.1 ; \mathrm{n}=2)$; tibia $1,031(933 ; \mathrm{n}=1)$, $1,145(1,117 \pm 79.9 ; \mathrm{n}=2)$ and $1,385(1,321 \pm 130.1 ; \mathrm{n}=$ 2); tarsomere I $650(608 ; n=1), 678(678 \pm 60.8 ; n=2)$ 


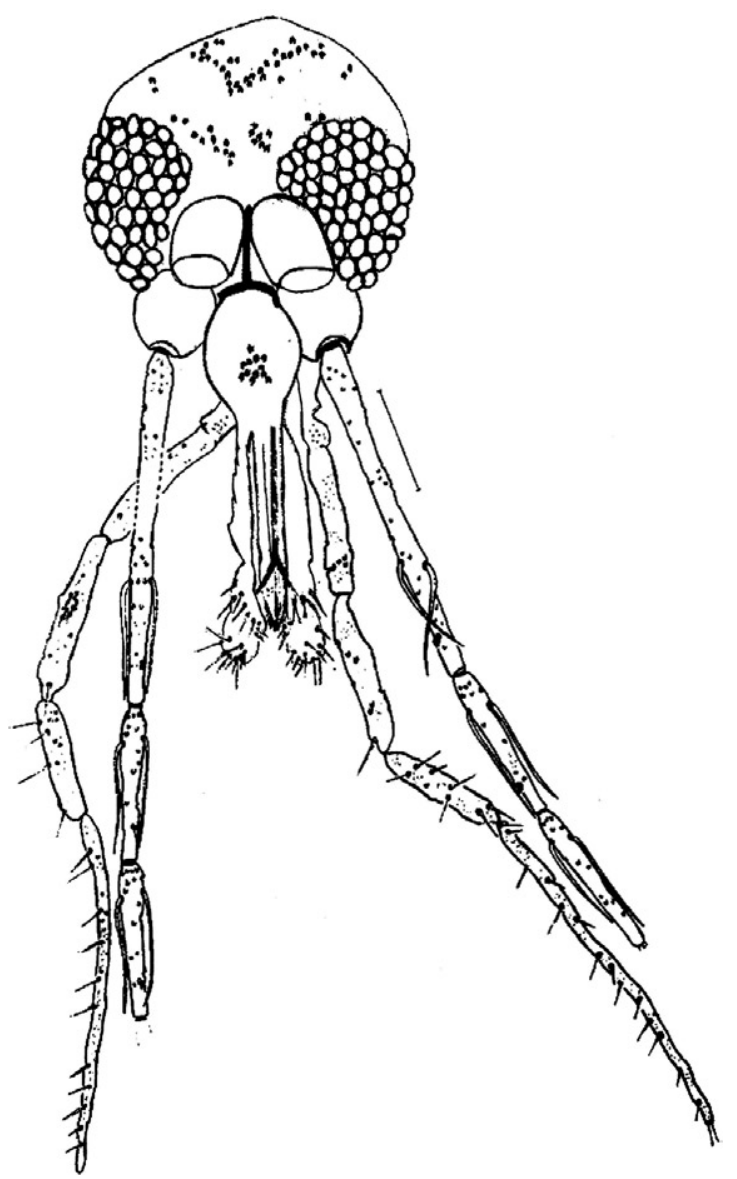

Fig. 1: Evandromyia grimaldii sp. nov. (paratype male). Head, frontal view. $\mathrm{Bar}=100 \mu \mathrm{m}$.

and $763(728 \pm 50.2 ; \mathrm{n}=2)$; tarsomeres II + III + IV + V $707(636 ; \mathrm{n}=1), 721(700 \pm 50.2 ; \mathrm{n}=2)$ and $763(735$ $\pm 60.1 ; \mathrm{n}=2)$. Gonostyle (Fig. 5) $170(165 \pm 14.1 ; \mathrm{n}=2)$ long, with four spines: one apical, the upper external and the lower external inserted on a long process (the lower external one being smaller than the upper one); internal one implanted in the base, much smaller than the other spines. Subterminal seta absent. Gonocoxite $240(252 \pm$ $16.2 ; \mathrm{n}=2)$ long and $99(101 \pm 2.1 ; \mathrm{n}=2)$ wide, with three long, broad setae inserted on the common tubercle. Paramere folded back on itself at apex, with many setae in this region. Lateral lobe $325(324 \pm 7.1 ; n=2)$ long and $32(25 \pm 4.9 ; \mathrm{n}=2)$ wide. Lateral lobe/gonocoxite ratio 1.35: $1(1.29 \pm 0.06 ; n=2)$. Conical aedeagus. Genital filament (Fig. 6) $480(501 \pm 24.7 ; \mathrm{n}=2)$ long and $6(7 \pm$ 1.94; $\mathrm{n}=2)$ wide and genital pump $231(208 \pm 41.7 ; \mathrm{n}=$ 2). Genital filament/genital pump ratio 2.08: 1 (2.46 \pm $0.61 ; n=2)$. Tip of genital filaments with light and asymmetrical narrowing.

Female (allotype) - sand fly of medium size, measuring $c a .2,600(2,706 \pm 285.6 ; \mathrm{n}=3)$ in length. Coloration as in the male. Head (Fig. 2) $424(417 \pm 32.1 ; n=3)$ long and $325(312 \pm 12.1 ; \mathrm{n}=3)$ wide. Head length/head width ratio 1.30 : $1(1.34 \pm 0.13 ; \mathrm{n}=3)$. Clypeus $141(135$

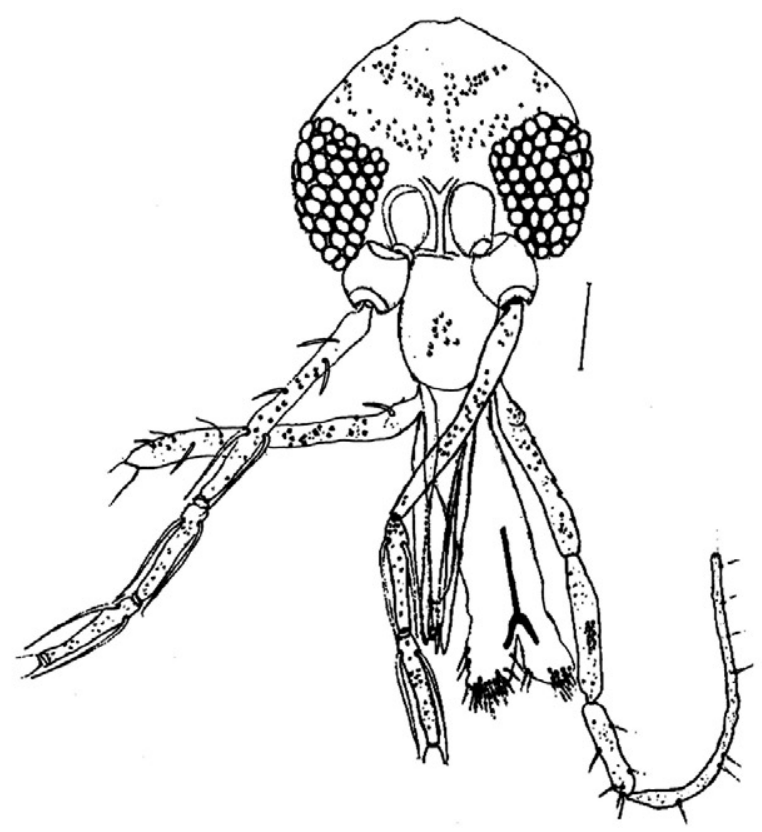

Fig. 2: Evandromyia grimaldii sp. nov. (paratype female). Head, frontal view. $B a r=100 \mu \mathrm{m}$.

$\pm 10.4 ; \mathrm{n}=3$ ) long; clypeus length/head length ratio 0.33 : $1(0.32: 1 \pm 0.01 ; \mathrm{n}=3)$. Eye $172(164 \pm 5.1 ; \mathrm{n}=3)$ long and $102(107 \pm 4.0 ; n=3)$ wide; eye length/head length $0.41(0.39: 1 \pm 0.02 ; \mathrm{n}=3)$. Interocular distance $144(120$ $\pm 9.9 ; \mathrm{n}=2)$. LE $305(298 \pm 22.5 ; \mathrm{n}=3)$. LE/head length 0.72: $1(0.72 \pm 0.01 ; n=3)$. Antenna with simple ascoid, extending beyond the apex of the segment. Antennomere lengths: AIII 287 (280 $\pm 19.8 ; \mathrm{n}=3)$; AIV 137 (132 \pm 10.7; $\mathrm{n}=3)$; AV $140(136 \pm 12.9 ; \mathrm{n}=3) ; \mathrm{AXV}$ and AXVI lost in allotype, AXV $>$ AXVI in paratypes $(n=3)$. AIII, AIV and AV with papilla; ratios: AIII/head length 0.68: 1 (0.67: $1 \pm 0.061 \mathrm{n}=3)$; AIII/LE 0.94: 1 (0.94: $1 \pm 0.01$; $\mathrm{n}=3$ ). Palpomeres 4 and 5 lost in allotype. Palpal formula 1.4.2.3.5 in paratypes $(\mathrm{n}=3)$. Palpomere lengths: P1 $42(40 \pm 4.0 ; \mathrm{n}=3) ; \mathrm{P} 2161(159 \pm 12.0 ; \mathrm{n}=3) ; \mathrm{P} 3$ 179 (170 $\pm 13.4 ; \mathrm{n}=3) ; \mathrm{P} 4117 \pm 10.4 ; \mathrm{n}=3$ (paratypes); P5 $338 \pm 16.2 ; n=3$ (paratypes). The Newstead spines implanted in the median region of the third palpomere. Cibarium with four well developed posterior (horizontal) teeth; the anterior (vertical) teeth situated below the posterior teeth and laterally in the cibarium are present in large number, with some elements in a horizontal position (Fig. 8). Sclerotized area is poorly defined and the sclerotized arch is complete. Unarmed pharynx. Lacinia of the maxilla with approximately 4-6 external teeth in a single longitudinal row. Ventrocervical sensillae present. Thorax with two $(2 ; n=3)$ proepimeral setae and anepisternal superior setae 18-19 $(15-17 ; \mathrm{n}=3)$ in number; setae on the anterior region of the katepisternum present. Wing (Fig. 4) measurement 2,289 (2,312 \pm $8.1 ; \mathrm{n}=3)$ long and $735(730 \pm 8.1 ; \mathrm{n}=3)$ at maximum width. Length/width ratio 3.65:1 (3.16: $1 \pm 0.02)$. Length of the vein sections: $\mathrm{R}_{5} 1,342(1,366 \pm 8.7 ; \mathrm{n}=3)$; alpha $707(712 \pm 8.1 ; \mathrm{n}=3)$; beta $198(188 \pm 8.1 ; \mathrm{n}=3)$; gamma 
$212(228 ; \mathrm{n}=3)$; delta $254(263 \pm 8.1 ; \mathrm{n}=3)$. Legs, anterior median and posterior, respectively: femur 876 (862 $\pm 39.6 ; \mathrm{n}=2), 834(820 \pm 8.1 ; \mathrm{n}=2)$ and $890(890 \pm 39.6$; $\mathrm{n}=2)$; tibia $1,017(1,032 \pm 60.1 ; \mathrm{n}=2), 1,201(1,187 \pm$ $79.9 ; \mathrm{n}=2)$ and $1,413(1,420 \pm 49.4 ; \mathrm{n}=2)$; tarsomere I $692(664 \pm 39.6 ; \mathrm{n}=2), 721(728 \pm 50.2 ; \mathrm{n}=2)$ and 820 $(799 \pm 50.2 ; \mathrm{n}=2)$; tarsomeres II+III+IV+V $735(742 \pm$ 9.9; $\mathrm{n}=2), 749(770 \pm 29.7 ; \mathrm{n}=2)$ and $791(806 \pm 20.5 ; \mathrm{n}$ =2). Spermathecae (Fig. 9): $32(33 \pm 1.7 ; \mathrm{n}=3)$ long by $25(24 \pm 2.3 ; \mathrm{n}=3)$ at maximum width. The body of the spermathecae presents superficial striations. The initial portion is rectangular finishing in a bottleneck about three times narrower than at its widest point. The head of the spermathecae present some fine bristles inserted in the apex of the bottleneck. The individual and common sperm ducts are smooth-walled, the latter being as long as the genital fork. The individual duct is $88(86 \pm$ $2.8 ; \mathrm{n}=2)$ in length and the common duct $56(92 \pm 14.8$; $\mathrm{n}=2)$. Cercus $137(168 \pm 25.2 ; \mathrm{n}=3)$ long.

Type-material - Holotype male and allotype female were collected with CDC light trap, in forest, in the locality of Reserva Biológica de Duas Bocas, district of Alto Alegre, municipality of Cariacica, ES, Brazil on 24 April 2008 (IS Pinto col.), together with two male and one female paratypes. Two female paratypes collected in the same locality on 20 June 2008 . The type-material is deposited in the Phlebotomine Collection of the Instituto de Pesquisas René Rachou-Fiocruz, Belo Horizonte, Minas Gerais, Brazil.

Etymology - The name Ev. grimaldii sp. nov. has been given in honor of Dr. Gabriel Grimaldi Filho, from the Fundação Oswaldo Cruz, for his contributions for the study on leishmaniases in Brazil.

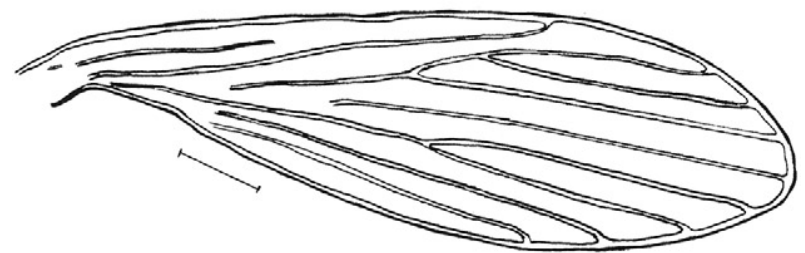

Fig. 3: Evandromyia grimaldii sp. nov. (holotype male). Wing. Bar $=100 \mu \mathrm{m}$.

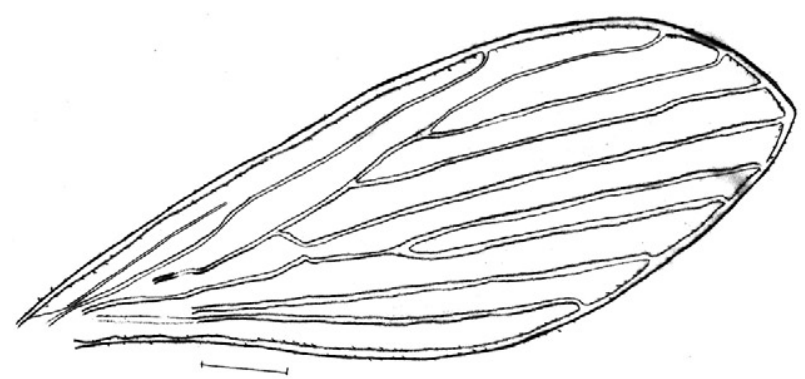

Fig. 4: Evandromyia grimaldii sp. nov. (allotype female). Wing. Bar $=100 \mu \mathrm{m}$.

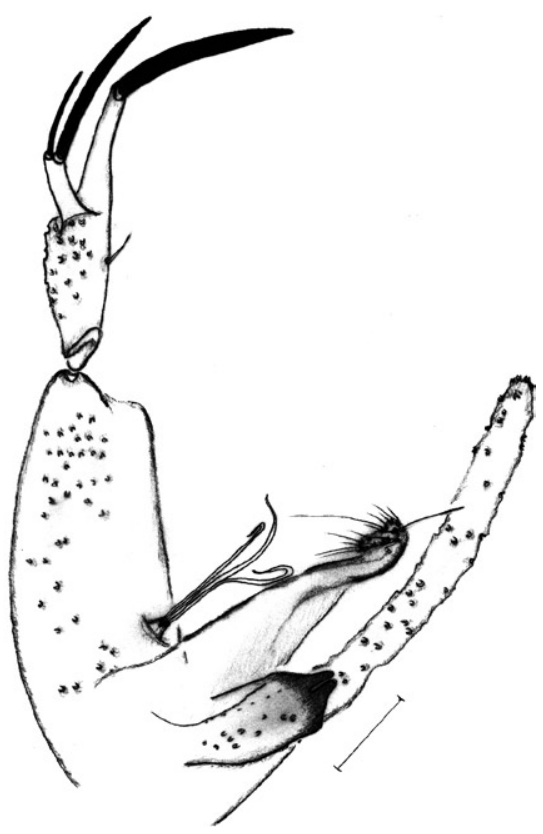

Fig. 5: Evandromyia grimaldii sp. nov. (holotype male). Terminalia. Bar $=100 \mu \mathrm{m}$.

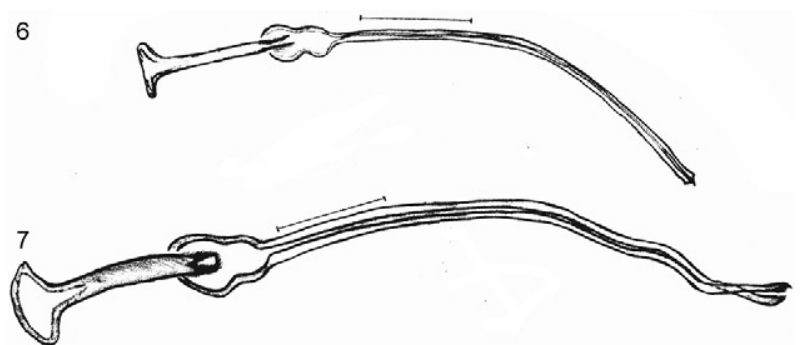

Figs 6, 7: genital pump and filaments. 6: Evandromyia rupicola (holotype male); 7: Evandromyia grimaldii sp. nov. (paratype male). $\operatorname{Bar}=100 \mu \mathrm{m}$.

\section{DISCUSSION}

At the moment, three species compose the series rupicola: Evandromyia rupicola (Martins Godoy \& Silva 1962), Evandromyia correalimai (Martins, Coutinho \& Luz 1970) and Evandromyia gaucha Andrade Filho, Souza \& Falcão 2007. Of these species only Ev. correalimai is known from both sexes (Martins et al. 1970). Ev. gaucha was described based on the female (Andrade Filho et al. 2007) and only males are known for Ev. rupicola (Martins et al. 1962), however EAB Galati, MLF Condino and $\mathrm{C}$ Casanova (unpublished observations) collected a female probably of Ev. rupicola species in the state of São Paulo, Brazil.

The female of Ev. correalimai does not present the body of the spermathecae with bottleneck and the horizontal teeth of the cibarium are not well developed. These structures are sufficient to distinguish Ev. cor- 


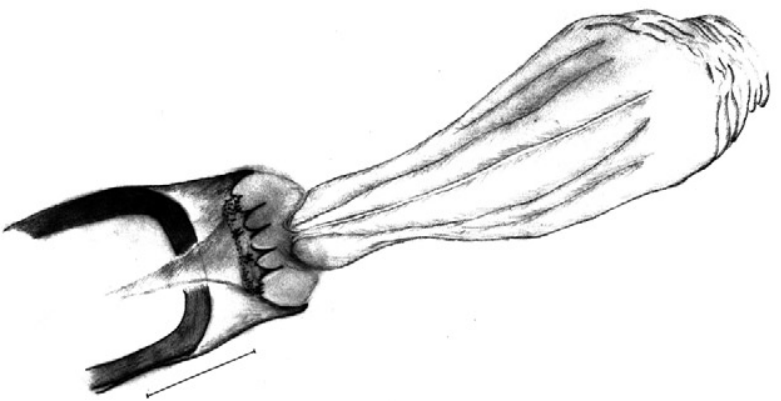

Fig 8: Evandromyia grimaldii sp. nov. (paratype female). Pharynx and cibarium. Bar $=100 \mu \mathrm{m}$.

realimai from $E v$. grimaldii. The male of new species present the internal spine much smaller than the others while in Ev. correalimai this spine is larger, similar to the lower external one.

Ev. gaucha was recently described and not identified with any known group of Evandromyia, although the authors recognize it as close to the species of the rupicola series (Andrade Filho et al. 2007). As the present authors had the opportunity to describe Ev. grimaldii, all the typespecimens of Ev. gaucha were examined to check for any morphological likeness between the two species and this determined the inclusion of Ev. gaucha in the series rupicola. The two species can be clearly distinguished by the spermathecae which are highly atypical in both.

The males of Ev r rupicola are very similar to $E v$. grimaldii, however, they can be distinguished by the genital filaments which are longer in the new species (minimum of 480 and maximum of 518) than those of $E v$. rupicola (Fig. 7). In holotype and three male paratypes of Ev. rupicola these filaments ranged between 364-371 $\mu \mathrm{m}$ (average of $367 \mu \mathrm{m}$ ) long. In accordance with Galati's information, the body of Ev. rupicola's spermathecae does not present a bottleneck as in Ev. grimaldii.

With the description of Ev. grimaldii, the serie rupicola is now composted of four species, all restricted to the Atlantic rain forest region. ES now has three endemics species, Lutzomyia souzalopesi Martins, Silva \& Falcão 1970, Lutzomyia falquetoi Pinto \& Santos 2007 and Ev. grimaldii, but new studies on phlebotomine sand flies are underway and other species may still be described and thus further increase the sand fly diversity of ES.

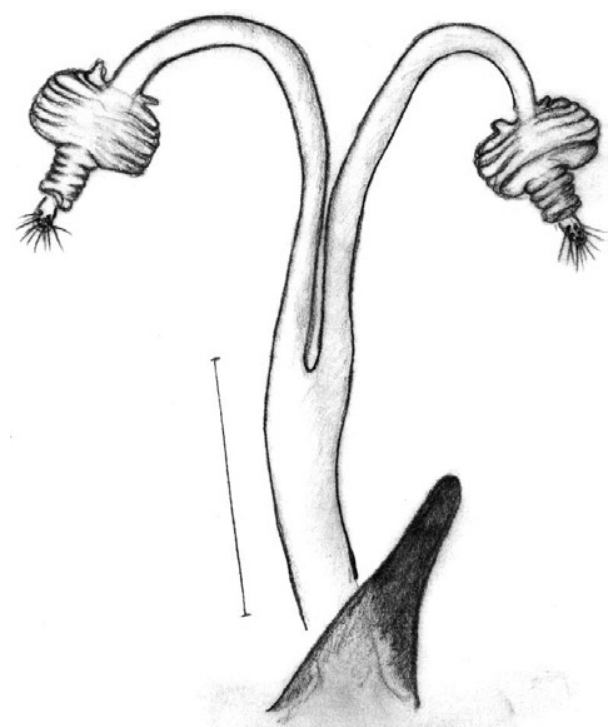

Fig 9: Evandromyia grimaldii sp. nov. (allotype female). Spermatheca. Bar $=100 \mu \mathrm{m}$

\section{ACKNOWLEDGEMENTS}

To Cristiani C. Sanguinette, for her help with the figure of the sand fly, and Reginaldo P. Brazil, for reading earlier drafts of the manuscript.

\section{REFERENCES}

Andrade Filho JD, Souza GD, Falcão AL 2007. Description of a new phlebotomine species, Evandromyia gaucha sp. nov. (Diptera: Psychodidae: Phlebotominae) from Rio Grande do Sul, Brazil. Mem Inst Oswaldo Cruz 102: 737-740.

Galati EAB 2003. Classificação de Phlebotominae. In EF Rangel, R Lainson (eds), Flebotomíneos do Brasil, Fiocruz, Rio de Janeiro, p. 23-51.

Marcondes CB 2007. A proposal of generic and subgeneric abbreviations for phlebotomine sandflies (Diptera: Psychodidae: Phlebotominae) of the world. Entomol News 118: 351-356.

Martins AV, Coutinho JO, Luz E 1970. Nova espécie de flebótomo do Estado do Paraná: Lutzomyia correalimai n. sp. (Díptera: Psychodidae). Rev Bras Malariol Doenças Trop 22: 189-200.

Martins AV, Godoy Jr, Silva JE 1962. Nota sôbre os flebtótomos de Petrópolis, estado do Rio de Janeiro, com a descrição de uma nova espécie. Rev Bras Biol 22: 55-60. 